\title{
Experimental infections with Enterocytozoon salmonis Chilmonczyk, Cox, Hedrick (Microsporea): an intranuclear microsporidium from chinook salmon Oncorhynchus tshawytscha
}

\author{
R. P. Hedrick*, J. M. Groff, D. V. Baxa \\ Department of Medicine, School of Veterinary Medicine, University of California, Davis, California 95616, USA
}

\begin{abstract}
Infections were induced in juvenile chinook salmon Oncorhw...' is tshawytscha by intraperitoneal injections of celis from the kidney of fish with naturally-uccurring infections of Enterocytozoon salmonis. A mild hyperplasia of the hematopoietic tissues of the kidney and spleen were observed $3 \mathrm{wk}$ after injection at water temperatures of $15^{\circ} \mathrm{C}$. By $5 \mathrm{wk}$ postinjection, populations of lymphoblasts, some of which contained intranuclear forms of the parasite, were abundant in the kidney and spleen but also occurred in the leptomeninges, skeletal muscle, coelomic mesenteries, hepatic sinusoids and periorbital connective tissues of the eye. Plasmodial stages were abundant within the nucleus of blast cells in stained kidney imprints from infected fish but spores were only rarely detected. At $7 \mathrm{wk}$ postinjection, the infections had progressed to a severe systemic disease with features similar to naturally-occurring infections with the microsporidium. These included anemia accompanied by a leukemic condition in which lymphoblastic cells were found disseminated throughout most tissues including prominent accumulations in the lamina propria of the posterior intestine. Mortalities occurred among infected fish between 53 and $60 \mathrm{~d}$ postinjection and infections were detected in most survivors at the end of the study at $9 \mathrm{wk}$ postinjection. Moderate numbers of spores were found most often in dead fish and survivors examined at the end of the study $(63 \mathrm{~d}$ ). The potential for treatment of infections with fumagillin $\mathrm{DCH}$ was demonstrated by the absence of mortalities and microscopic signs of clinical infections and a marked decrease in detection of the parasite among chinook salmon fed the drug $(0.1 \mathrm{~g}$ $\mathrm{kg}^{-1}$ food at $1.5 \%$ body weight $\mathrm{d}^{-1}$ ) between 3 and 7 wh postinjection.
\end{abstract}

\section{INTRODUCTION}

Intranuclear microsporidia were first detected in salmonid fish by Modin (1981). He found Microsporidium rhabdophilia in the nuclei of the rodlet cells of several salmonid species reared in freshwater in California, USA, but there was no evidence of its association with clinical disease. In contrast, Elston et al. (1987) determined that an intranuclear microsporidium of hematopoietic cells was the cause of an anemia among 3 yr old chinook salmon Oncorhynchus tshawytscha reared in seawater net pens in Washington state, USA. A similar or possibly identical disease was later described among juvenile chinook salmon from fresh-

Addressee for correspondence; present address: Laboratoire d'ichtyopathologie, INRA, Domaine de Vilvert, F-78350 Jouyen-Josas, France water in Washington (Morrison et al. 1990) and California (Hedrick et al. 1990). The infections of both adult and juvenile chinook were characterized by anemia and a chronic and severe lymphoblastosis (Morrison et al. 1990) with features of leukemia (Hedrick et al. 1990). Affected lymphoblasts often contained intranuclear stages of a microsporidium which was presumed to be the cause of the unusual proliferation associated with this cell population. The microsporidian infections shared certain similarities to a plasmacytoid leukemia in adult chinook salmon reared in seawater as described by Kent et al. (1990). However, experimental transmission studies of the plasmacytoid leukemia have not demonstrated a role of the microsporidium in the observed disease (Kent \& Dawe 1990).

An in-depth electron microscopy study of the parasite associated with the infection in juvenile chinook salmon was conducted by Chilmonczyk et al. (1991). 
They demonstrated that the principal cell type infected was a hematopoietic stem cell (lymphoblast) although several other cell types were susceptible. The intranuclear location and unique developmental features of the parasite were used to classify the microsporidium as Enterocytozoon salmonis (Chilmonczyk et al. 1991). Although structural details on the developmental stages of the parasite are now known, the pathogenesis of the disease is poorly understood. The purpose of the current paper was to examine the progress of experimental infections with the parasite in juvenile chinook salmon and to investigate the potential of an antimicrosporidian compound, fumagillin $\mathrm{DCH}$, as a treatment for the disease. The drug was tested because of its known effect against microsporidian infections in sevcral animal species (Kătziielson \& Jamieson 1952 . Bailey 1953, Kano et al. 1982) and because of the authors' familiarity with the effective administration protocols from previous studies in treating myxosporean infections in salmonid fish (Hedrick et al. 1988, Wishkovsky et al. 1990).

\section{MATERIALS AND METHODS}

Fish. Juvenile chinook salmon $(50 \mathrm{~g})$ with clinical Enterocytozoon salmonis infections were obtained directly from the Darrah Springs Hatchery, State of California, Department of Fish and Game (CDFG). Uninfected juvenile chinook salmon were reared from eggs in the laboratory. The eggs were treated on arrival with $100 \mathrm{ppm}$ of an iodophor solution (Argent) for $10 \mathrm{~min}$ and incubated thereafter in $12^{\circ} \mathrm{C}$ well water. After hatching, the fish were fed commercial salmon rations (Biodiet). Beginning $4 \mathrm{wk}$ prior to experimentation the fish were shifted to $15^{\circ} \mathrm{C}$ well water and dry trout rations (Silverking). The fish had an average weight of $9.5 \mathrm{~g}$ when used for the experimental infection trial.

Experimental infections. The kidneys from 2 chinook salmon with naturally-occurring clinical infections were removed and placed into separate petri dishes. A small fragment of each was used to make an imprint which was later stained with Leishman-Giemsa reagents to confirm the presence and to estimate the numbers of cells with parasites. Each of the remaining portions of the kidneys were mixed with $7 \mathrm{ml}(1: 10 \mathrm{wt} /$ vol) of minimal essential medium (MEM), without antibiotics or serum. The medium and kidney were then forced through a 40 mesh screen with a glass rod to obtain cell suspensions. The 2 cell suspensions were used for intrapcritoneal injections of 2 groups of 50 chinook salmon (0.1 ml containing ca $10^{6}$ cell fish $\left.^{-1}\right)$. An additional group of 50 fish received an intraperitoneal injection with $0.1 \mathrm{ml}$ of MEM only. Each group of 50 fish was placed into 1301 rectangular tanks supplied with $15^{\circ} \mathrm{C}$ well water and air stones. At 3 wk postinjection, samples were taken from the fish in each group before they were subdivided into two $130 \mathrm{l}$ tanks with 23 or 24 fish. The fish were maintained under these conditions until the end of the study at $9 \mathrm{wk}$ postinjection.

Progress of experimental infections. The progress of experimental infections was followed by examination of blood (hematocrit and leucocrit), selected tissues after histological preparation and stained imprints from the kidney. At 3, 5, 7 and $9 \mathrm{wk}$ postinjection, 5 fish were removed from each group. The fish were anesthetized in $0.07 \mu \mathrm{g} \mathrm{ml^{-1 }}$ of tricaine methanesulfonate (MS-222) and blood was collected from the caudal artery into microhematocrit tubes. The hematocrit and leucocrit were then determined for each fish (Ravel 1973, McLeay \& Gordon 1977).

Portions of the kidney, spleen, liver, intestine, eye, body musculature, gill, heart and brain were placed into Davidson's fixative (Humason 1979). After $16 \mathrm{~h}$ of fixation, the samples were transferred to $70 \%$ ethanol and processed for standard paraffin embedding and sectioning. Tissue sections $(5 \mu \mathrm{m})$ were stained with hematoxylin and eosin. Imprints made directly from kidney tissues were air-dried for $30 \mathrm{~min}$, fixed in $100 \%$ methanol for 5 min and stained with Leishman-Giemsa (Yasutake \& Wales 1983). Tissues from mortalities that occurred between 53 and $60 \mathrm{~d}$ postinjection were prepared as for live fish with the exception that no blood samples were available.

Fumagillin diets. The potential efficacy of fumagillin DCH for treatment of Enterocytozoon salmonis infections was examined by feeding the drug to replicate groups of experimentally infected chinook salmon. Fumagillin was added to the rations by dissolving the drug in $95 \%$ ethanol $\left(100 \mathrm{ml}\right.$ alcohol $\mathrm{kg}^{-1}$ feed) and spraying directly onto a commercial pelleted feed to

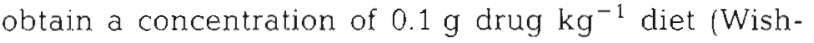
kovsky et al, 1990). The pellets were then coated by spraying with a mixture of alcohol and cod liver oil $(50 \mathrm{ml}$ of each $\mathrm{kg}^{-1}$ feed), dried at room temperature and then stored at $-20{ }^{\circ} \mathrm{C}$ until used. Control diets were prepared in the same manner but did not contain the drug.

Control diets were fed to all fish for $3 \mathrm{wk}$ following injection. Medicated diets were then fed for $4 \mathrm{wk}$ to one replicate from each of the 2 experimentally infected groups (infected medicated) and to one replicate from the control group (uninfected medicated). During this 4 wk treatment period the remaining experimental (infected unmedicated) and control (uninfected medicated) replicates received control diets. After this period, all fish received control diets until the end of the study at $9 \mathrm{wk}$ postinjection. All diets were fed at $1.5 \%$ body weight $\mathrm{d}^{-1}$ throughout the study 
Statistics. Paired student $t$-tests $(\mathrm{p}<0.05)$ were used to compare the mean hematocrit and leucocrit values of experimental groups to the control group within each treatment (e.g. unmedicated or medicated) at each sampling date.

\section{RESULTS}

Cell suspensions made from naturally infected chinook salmon used to inoculate the fish contained ca $10^{6}$ cells. As determined from stained kidney imprints, 10 to $20 \%$ of the cells in this suspension were estimated to be infected with plasmodial stages of the microsporidium. Experimental infections were successfully established by intraperitoneal injections of these cell suspensions into previously healthy juvenile chinook salmon (Table 1).

There were no external clinical signs of disease until $53 \mathrm{~d}$ following injections when the first mortalities occurred. A total of $10 \mathrm{fish}$, all from the infected unmedicated groups died between 53 and $60 \mathrm{~d}$ postinjection ( 6 in Group 1 and 4 in Group 2). The progress of experimental infections was evaluated by determining hematocrits, leucocrits, and the presence of the microsporidium and associated pathological changes in kidney imprints and tissue sections among medicated and unmedicated fish from each group at $3,5,7$ and 9 wk postinjections.

\section{3 wk postinjection}

There were no differences between the hematocrits and leucocrits among the groups. Pathological changes were principally restricted to a mild hyperplasia of hematopoietic cells in the kidney and spleen of fish injected with the parasite. A small number of blast-like cells (lymphoblasts) occurred in the pseudobranch, the hepatic sinusoids and the mesenteries surrounding the pancreatic tissues and in association with the reticuloendothelial cells of the heart. The only change detected in uninfected control fish was a mild hyperplasia of the gill epithelium in one fish. Plasmodial stages of the parasite were not detected among the fish examined in either histological sections or stained kidney imprints.

\section{5 wk postinjection}

There were no differences detected in hematocrits or leucocrits in the infected or uninfected groups. However, the number of lymphoblasts in the hematopoietic tissues (kidney and spleen) of infected fish had markedly increased compared to that observed at the $3 \mathrm{wk}$ examination. In addition, lymphoblasts occurred in the leptomeninges, periorbital connective tissue and choroid gland of the eye, submucosa of the olfactory epithelium and the oropharynx, and the lamina propria of the posterior intestine. Plasmodial stages of the parasite were detected in lymphoblasts at this time and though rare, spores were detected in 1/5 fish from each of the infected unmedicated groups (Table 1). There was no evidence of parasites or pathological changes in fumagillin-medicated or control fish.

\section{7 wk postinjection}

There was a significant decrease $(p<0.05)$ in the mean hematocrits of both groups of infected unmedi-

Table 1. Oncorhynchus tshawytscha. Experimental infections with Enterocytozoon salmonis in juvenile chinook salmon receiving normal (unmedicated) or fumagilin $\left(0.1 \mathrm{~g} \mathrm{~kg}^{-1}\right)$ medicated diets

\begin{tabular}{|c|c|c|c|c|c|}
\hline \multirow[t]{2}{*}{ Group } & \multicolumn{4}{|c|}{ Weeks postinjection } & \multirow{2}{*}{ Mortalities $^{c}$} \\
\hline & 3 & 5 & 7 & 9 & \\
\hline \multicolumn{6}{|l|}{ Control } \\
\hline Unmedicated & $0 / 5^{\mathrm{a}}(0 / 5)^{\mathrm{b}}$ & $0 / 5(0 / 5)$ & $0 / 5(0 / 5)$ & $0 / 5(0 / 10)$ & 0 \\
\hline Medicated & & $0 / 5(0 / 5)$ & $0 / 5(0 / 5)$ & $0 / 10(0 / 10)$ & 0 \\
\hline \multicolumn{6}{|l|}{ Group 1} \\
\hline Unmedicated & $1 / 5(0 / 5)$ & $5 / 5(\mathrm{nd})$ & $3 / 4(5 / 5)$ & $5 / 5(5 / 5)$ & $66 / 6(6 / 6)$ \\
\hline Medicated & & $0 / 5(0 / 5)$ & $0 / 5(0 / 5)$ & $0 / 10(3 / 10)$ & 0 \\
\hline \multicolumn{6}{|l|}{ Group 2} \\
\hline Unmedicated & $0 / 5(0 / 5)$ & $1 / 5(1 / 5)$ & $5 / 5(4 / 5)$ & $5 / 7(5 / 7)$ & $44 / 4(4 / 4)$ \\
\hline Medicated & & $0 / 5(0 / 5)$ & $0 / 5(0 / 5)$ & $0 / 10(1 / 10)$ & 0 \\
\hline \multicolumn{6}{|c|}{$\begin{array}{l}{ }^{a} \text { Evidence for infections as determined by lymphoblastosis and plasmodial stages following histological examinations (no. of } \\
\text { fish with microscopic signs/no. fish examined) } \\
\text { b Plasmodial or spore stages detected in stained kidney imprints (no. of fish positive/no. fish examined) } \\
\text { c Mortalities occurred between } 53 \text { and } 60 \text { d postinjection }\end{array}$} \\
\hline
\end{tabular}


cated fish (21.2 and $26.2 \%$ ) compared to $50 \%$ in the control group (Fig. 1A). Leucocrits also reached the highest values observed in individual fish ( 5 to $8 \%$ ) in the infected unmedicated groups but the wide variation among fish (range 0.5 to $8 \%$ ) resulted in a lack of significant differences between the means of the experimental groups and the control (Fig. 1B). Microscopic observations of tissues from infected unmedicated groups showed all but one fish had severe systemic infections and large numbers of blast-like cells were found in the lamina propria of the posterior intestine. Numerous plasmodial forms of the parasite were found in the nucleus of lymphoblasts as observed both in tissue sections and kidney imprints. Spores were observed in only 1 fish from Group 1 . No evidence for parasite infections were detected in the control fish or among fish medicated with fumagillin (Table 1). However, a mild depletion of the hematopoietic tissues in the kidney and spleen of all fish medicated with fumagillin was observed.

\section{9 wk postinjection}

Although the mean hematocrits of both unmedicated experimental groups (29.2 and $29.4 \%$ for Groups 1 and 2 respectively) were lower than the unmedicated con- trol group (41.8\%), these differences were not significant at $p<0.05$. The hematocrits among all medicated groups were similar but showed a declining trend from the initial samplings (Fig. 1C). Leucocrits were similar in all medicated and unmedicated groups (Fig. 1B, D). The severity of the infections was less pronounced in unmedicated Group 1 fish compared to the 7 wk sample but infections among Group 2 fish were equal to or greater than the previous examination. Spores were more abundant compared to earlier samples and were detected in 2 fish from Group 1 and one fish from Group 2. A mild increase in lymphoblasts, particularly in the coelomic mesenteries was detected among several fish in both infected groups previously medicated for $4 \mathrm{wk}$ with fumagillin. Among fish in these 2 groups (3 in Group 1 and 1 in Group 2) low numbers of plasmodial stages were detected in tissue sections and kidney imprints (Table 1).

\section{Mortalities}

Mortalities were first detected $53 \mathrm{~d}$ postinjection among the unmedicated infected fish (Table 1). By $60 \mathrm{~d}$ postinjection, 10 fish had died and these were all severely infected with the microsporidium as demonstrated by histological examinations and presence of

No Drug Treatments
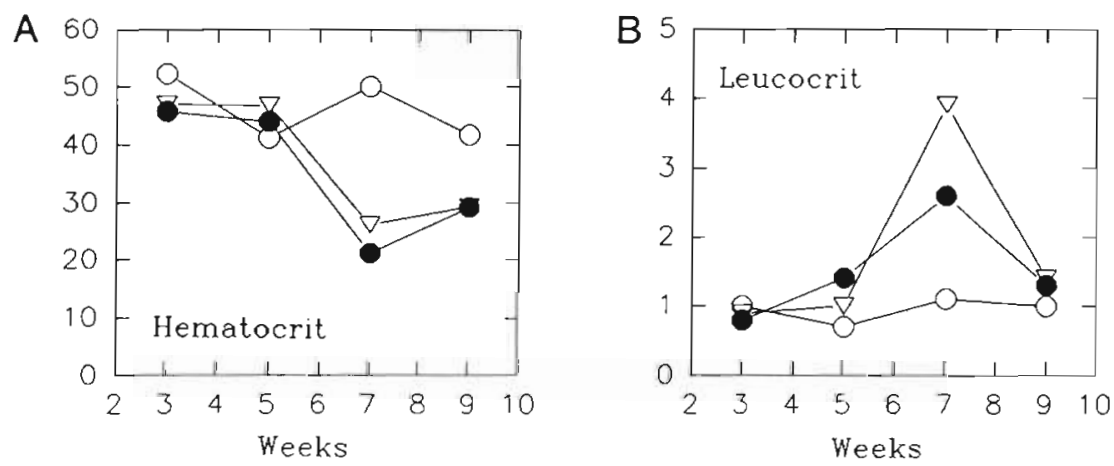

Fumagillin-Treated
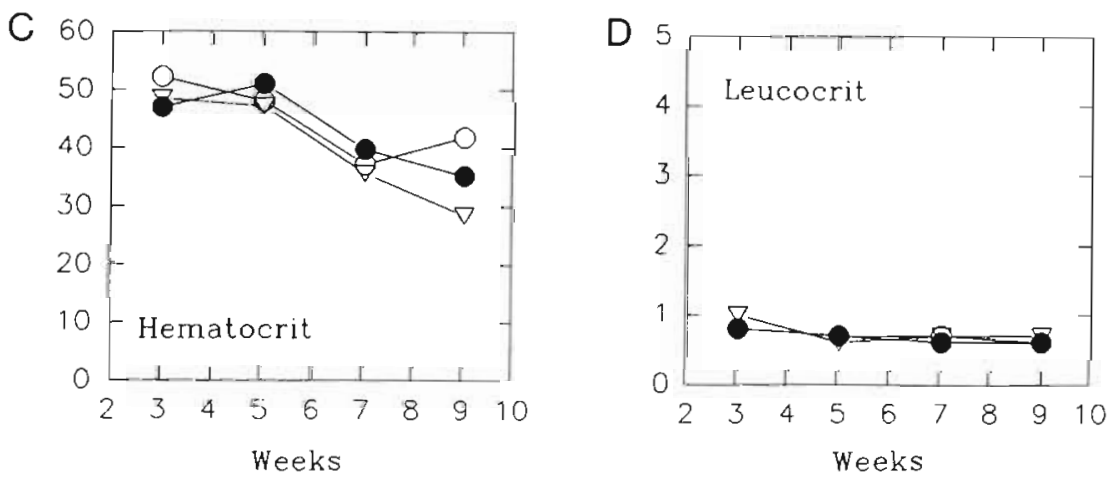

Fig. 1. Oncorhynchus tshawytscha. Mean hematocrits and leucocrits among 2 groups (- Group $1 ; \nabla$, Group 2) of chinook salmon experimentally infected with Enterocytozoon salmonis either unmedicated or receiving $4 \mathrm{wk}$ treatments with fumagillin DCH at $0.1 \mathrm{~g} \mathrm{~kg}^{-1}$ feed at $1.5 \%$ body weight $\mathrm{d}^{-1}$ beginning 3 wk postinjection, compared to uninfected controls (O). (A) Hematocrits and (B) leucocrits of infected and control unmedicated groups. (C) Hematocrits and (D) leucocrits of infected and control groups receiving drug treatments 
the parasites in kidney imprints (Table 1). These fish had grossly swollen kidneys, spleens and posterior intestines.

\section{DISCUSSION}

Experimental Enterocytozoon salmonis infections, with features identical to those observed in naturally occurring outbreaks, were induced by intraperitoneal injections of infected kidney cells. The experimental disease was characterized by the progressive invasion of tissues with affected lymphoblasts which resulted in a leukemic-like condition. Accompanying the leukemic condition was an associated anemia followed by mortality in severely affected fish.

Although intranuclear microsporidian infections among salmonid fish were detected by Modin (1981), their role as causes of disease were only described later (Elston et al. 1987, Hedrick et al. 1990, Morrison et al. 1990). The latter 3 studies described naturally-occurring infections among farm or hatchery populations which were characterized by a prolonged course of low grade mortality with the most prominent clinical signs being a lymphoblastosis or leukemic-like condition and anemia. In our experimental studies, both features of the clinical infection were induced following injections of cell suspensions from naturally infected fish. Unfortunately, the dose of parasite injected into each fish could not be precisely determined because at present we have no reliable method for enumeration of the parasite. Detection of plasmodial stages in imprints from donor fish was used as a rough estimate of the parasite dose in the inoculum (ca 10 to $20 \%$ of the kidney cells infected). The 2 kidneys used to prepare the cells suspensions for injection were judged to be heavily infected by the number of cells bearing plasmodia and spores in the nucleus.

At the doses used and at a water temperature of $15^{\circ} \mathrm{C}$ the disease became clearly apparent at $53 \mathrm{~d}$ postinjection when the first mortalities occurred. The mortalities occurred shortly after the most severe anemia (mean hematocrits of 21.2 and $21.6 \%$ for Group 1 and 2 respectively) was detected $7 \mathrm{wk}$ postinjection in the infected unmedicated groups. The mean hematocrit for the uninfected unmedicated control group was $50.0 \%$ at this time (Fig. 1A). Although hematocrits in natural outbreaks have been reported to be as low as 5 to $17.5 \%$, a mean nearer to 20 or $25 \%$ can be expected in an infected population (Elston et al. 1987. Hedrick et al. 1990).

Mortalities that occurred between 53 and $60 \mathrm{~d}$ postinjection in our study had severe infections and gross internal signs including swollen kidneys, spleens and posterior intestines similar to observations in natural outbreaks (Hedrick et al. 1990, Morrison et al. 1990). Other potential causes for the mortalities in our experimental studies were not explored because most fish had been dead for several hours before collection. However, we presume from the nature and extent of the clinical signs that the microsporidian infection was the underlying cause of mortality.

The potential therapeutic effects of fumagillin were demonstrated by the positive effects exerted in preventing the onset and severity of infections in fish medicated with the drug compared to their parallel unmedicated groups. The 4 wk treatment with $0.1 \mathrm{~g}$ $\mathrm{kg}^{-1}$ feed arrested mortality and delayed the severity of the disease and numbers of parasites observed. The lymphocyte proliferation and plasmodial stages observed in the fish examined at the end of the study however, may indicate that the drug had a static rather than parasiticidal effect. Recurrences of infection following fumagillin treatments have been described for Pleistophora anguilla infections in Japanese eels Anguilla japonica by Kano et al. (1982) and microsporidian infections in insects (Lynch \& Lewis 1971). Studies of longer duration are planned to determine whether clinical infections might have recurred in fish after the 4 wk treatments.

The mild hematopoietic depletion and a declining trend in hematocrits (Fig. 1C) but not leucocrits (Fig. 1D) among fish medicated with fumagillin have been recognized as a potential side effect of the drug (Lauren et al. 1989, Wishkovsky et al. 1990). This effect, however, is reversible once the drug is removed as demonstrated by studies in rainbow trout Oncorhynchus mykiss and chinook salmon (unpubl.).

The indications from our study suggest that infections are usually progressive and potentially fatal when no drug treatment is applied. Studies designed to investigate this more thoroughly are however underway with chinook salmon held both in freshwater and seawater after injection of the parasite. The mortalities would suggest that the infections were most severe at 53 to $60 \mathrm{~d}$ postinjection but Group 1 fish examined at the end of the study (63 d) were still severely infected. In our previous studies with experimentally infected kokanee salmon, $87 \%$ of the fish died by $45 \mathrm{~d}$ at water temperatures of $12{ }^{\circ} \mathrm{C}$ (Hedrick et al. 1990).

The eventual cause of death in experimentally infected fish is not known. We presume however, that the progressive spread of lymphoblasts from sites of proliferation (principally the kidney and spleen) via the vasculature and their replication in distant tissues results in a leukemic-like condition which alone can be fatal as demonstrated for the plasmacytoid leukemia of adult chinook salmon (Kent \& Dawe 1990, Kent et al. 1990). The significant drop in hematocrits and impairment of the critical function of other organs (kidney, 
liver, posterior intestine) may cause death directly. The immunosuppressive effect of the leukemic condition is also suspected as the underlying cause of secondary infections and this in combination with poor or marginal water quality would be expected to contribute to the chronic mortality observed in natural outbreaks.

The plasmodial stage of Enterocytozoon salmonis was the principal stage associated with all progressive phases of the disease. Spores were not frequent in the fish examined in our study. Our experiences with naturally-occurring infections indicate that there can be rather great differences in both the number of cells which harbor spores and the number of spores per cell. The paucity of spores observed in most infections lead us to conclude that plasmodial stages must be segregating with the nuclel of intected lymphoblasts as they divide since the spore stage is the only known infective stage of the microsporida (Canning \& Lom 1986).

Acknowledgements. This work was supported in part by Dingell-Johnson/Wallop-Breaux Fish Restoration Act funds administered through the California Department of Fish and Game and by the Institut National de la Recherches Agronomique. Thanks to the technicians of the Veterinary Medicine Teaching Hospital for their preparations of stained tissue sections for light microscopy

\section{LITERATURE CITED}

Bailey, L. (1953). The effect of Fumagillin upon Nosema apis (Zander). Nature, Lond. 171: 212-213

Canning, E. M., Lom, J. (1986). The microsporida of vertebrates. Academic Press, London

Chilmonczyk, S., Cox, W. T., Hedrick, R. P. (1991). Enterocytozoon salmonis $\mathrm{n}$. sp.: an intranuclear microsporidium from salmonid fish. J. Protozool (in press)

Elston, R. A., Kent, M. L., Harrell, L. H. (1987). An intranuclear microsporidium associated with acute anemia in the chinook salmon. J. Protozool. 34: 274-277

Hedrick, R. P., Groff, J. M., Foley, P., McDowell, T (1988). Oral administration of Fumagillin $\mathrm{DCH}$ protects chinook salmon Oncorhynchus tshawytscha from experimentally

Responsible Subject Editor. W. Körting, Hannover, Germany induced proliferative kidney disease. Dis. aquat. Org. 4: $165-168$

Hedrick, R. P., Groff, J. M., McDowell, T S., Willis, M., Cox, W. T (1990). Hernatopoietic intranuclear microsporidian infections with features of leukemia in chinook salmon Oncorhynchus tshawytscha. Dis. aquat. Org. 8: 189-197

Humason, G. L. (1979). Animal tissue techniques. W. H. Freeman, San Francisco

Kano, T., Okauchi, T., Fukui, H. (1982). Studies on Pleistophora infection in eel, Anguilla japonica - II. Preliminary tests for application of fumagillin. Fish Pathol. 17: 107-114

Katznelson, H., Jamieson, C. A. (1952). Control of Nosema disease of honey bees with fumagillin. Science 115: 70-71

Kent, M. L., Dawe, S. C. (1990). Experimental transmission of a plasmacytoid leukemia of chinook salmon (Oncorhynchus tshawytscha). Cancer Res. (suppl.) 50: 5679-5681

Kent, M. L., Groff, J. M., Traxler, G. S., Zinkl, J. G., Bagshaw, J. W. (1990). Plasmacytoid leukemia in seawater reared chinouk saimion Oncombynchus lohawyischa. Dis. dquat. Org. 8: 199-209

Lauren, D. J., Wishkovsky, A., Groff, J M., Hedrick, R. P., Hinton, D. E. (1989). Toxicity and pharmacokinetics of the antibiotic, fumagillin, in yearling rainbow trout (Salmo gairdneri). Toxicol. appl. Pharmacol 98: 444-453

Lynch, R. E., Lewis, L. C. (1971). Reoccurrence of the microsporidian Perezia pyraustae in the European corn borer, Ostrina nubilialis, reared on diet containing Fumadil B. J. Invertebr Pathol. 17: 234-236

McLeay, D. J., Gordon, R. C. (1977). Leucocrit: a simple hematological technique for measuring acute stress in salmonid fish including stressful concentrations of pulpmill effluent. J. Fish. Res. Bd Can. 34: 2164-2175

Modin, J. C. (1981). Microsporidium rhabdophilia n. sp. from rodlet cells of salmonid fishes. J. Fish Dis. 4: 203-211

Morrison, J. K., MacConnell, E., Chapman, P. F., Westgard, R. L. (1990). A microsporidium-induced lymphoblastosis in chinook salmon Oncorhynchus tshawytscha in freshwater. Dis. aquat. Org. 8: 99-104

Ravel, R. (1973). Clinical laboratory medicine, 2nd edn. Year Book Medical Publications, Chicago, p. 11-19

Wishkovsky, A., Groff, J. M., Lauren, D. J., Toth, R. J., Hedrick, R. P. (1990). Efficacy of fumagillin against proliferative kidney disease and its toxic side effects in rainbow trout (Oncorhynchus mykiss) fingerlings. Fish Pathol. 25: $141-146$

Yasutake, W. T., Wales, J. H. (1983). Microscopic anatomy of salmonids: an atlas. US Department of the Interior, Fish and Wildlife Service, Resource Publication 150, Washington, D.C.

Manuscript first received: November 12, 1990

Revised version accepted: January 15, 1991 